What a trip:

Clinical researchers go on sabbatical at

government agency

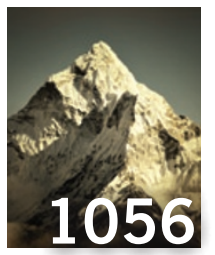

Peak health:

One man's quest

to combat altitude

sickness

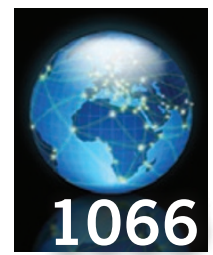

The big picture:

Global health

governance needs

fixing, experts say

\title{
Breakup of genetics advisory panel seen as premature
}

In September, Steven Teutsch received word that the expert panel he chaired, which advised the US Department of Health and Human Services (HHS) on how genetic technologies could be best integrated into health care, was to be abruptly disbanded in two weeks' time.

"We didn't anticipate the committee would end," says Teutsch, chief science officer of the Los Angeles County Health Department. "We were a bit surprised, because we had planned to continue this work that we had started."

Since its inception in 2002, the US Secretary's Advisory Committee on Genetics, Health and Society (SACGHS) helped push passage of the Genetic Information Nondiscrimination Act, which bars employers and health insurers from discriminating against individuals on the basis of their genetic information, and produced timely reports on gene patents and directto-consumer genetic testing, among other fractious topics. With the growing possibility of affordable whole-genome sequencing, many committee members and onlookers expected the panel to have an ongoing role in hashing out the clinical, ethical and legal implications of rapidly developing genomic technologies. But HHS Secretary Kathleen Sebelius, stating that the SACGHS had addressed all its "major topics," decided not to renew the committee's charter beyond 23 September.

Critics say this move was premature. "The question is, have all the issues been identified and examined in enough depth yet? And I think most of us in the field would probably argue that the answer is no," says former SACGHS member Huntington Willard, who directs the Duke Institute for Genome Sciences \& Policy in Durham, North Carolina.

In a final meeting last month, the SACGHS completed a report on genetics education and collected its final thoughts on several investigations launched in the past year, including a study into the implications of widespread personal genome data. Although the committee has an additional six months to wrap up any administrative tasks, there won't be time to produce full reports on the outstanding topics, so the committee will simply make written recommendations in a final letter to Sebelius, says Teutsch.

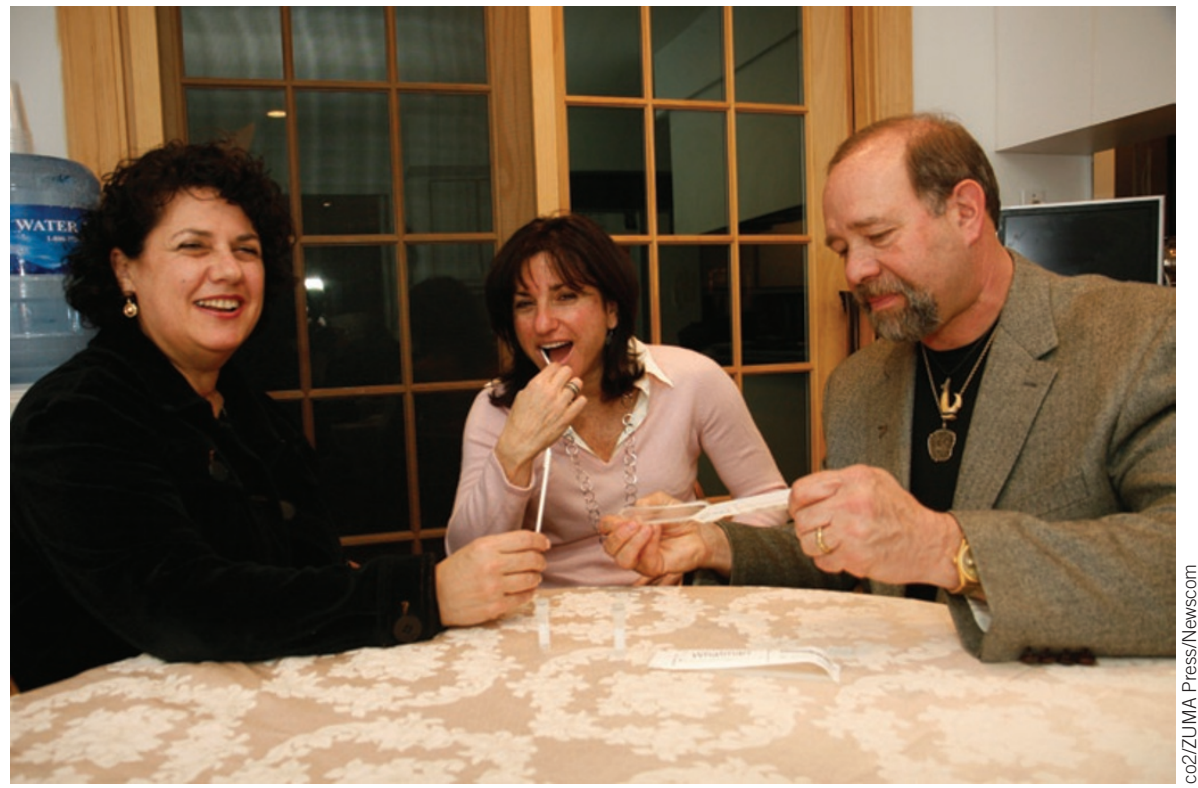

Be advised: Both the US and UK have cut expert bodies that monitor genetic testing.

According to US National Institutes of Health (NIH) spokesperson John Burklow, the void left by the dissolution of the SACGHS is expected to be filled by existing government advisory committees, including the Presidential Commission for the Study of Bioethical Issues, the Secretary's Advisory Committee on Heritable Disorders in Newborns and Children and numerous advisory groups at the NIH.

\section{Tight squeeze}

Burklow hinted at funding issues as a potential reason for shutting down the SACGHS, although critics say the amount of money needed to maintain the group was relatively small. In contrast, cost-cutting was cited in the UK government's decision last month to deepsix its corresponding advisory committee, the Human Genetics Commission, which will be replaced by a panel of experts working for the country's Department of Health.

Although there are other mechanisms for providing input into issues related to genomic medicine, the closing of the SACGHS "sends a message - and the message it sends is a little bit scary," says David Magnus, a bioethicist at the Stanford Center for Biomedical Ethics in
California. "As we move forward with figuring out how to integrate genomics into clinical care, there's a whole range of new problems that are just barely being addressed." For example, informed consent policies will need to change to give patients even a basic understanding of the implications of diagnostics that incorporate full sequencing. And direct-to-consumer genetic tests from various companies differ in how they interpret analyses-"but there is no way of knowing which is correct," Magnus says.

Some insist that the committee's adjournment signals not a declining commitment to the integration of genetic technologies into health care, but rather the elimination of redundancies. "The risk here is that people will misinterpret what it means as sort of a turning of the administration's back on the issues, and I personally don't interpret it that way," Willard says. Instead, he says, the time has come to stop talking about the possibility of genetic technologies and start making genomic medicine a reality. But, as SACGHS member Charis Eng, a geneticist at the Cleveland Clinic, points out: "this step will be the most difficult."

Kelly Rae Chi 